\title{
AIEPI: una estrategia ausente por la distancia en comunidades vulnerables
}

\section{Sr. Editor:}

La estrategia AIEPI (Atención Integrada a las Enfermedades Prevalentes de la Infancia) es una estrategia internacional promovida por la OPS/ OMS y la UNICEF. Incluye medidas de promoción, prevención, diagnóstico precoz y tratamiento de las enfermedades más prevalentes en la infancia, tales como: Infección Respiratoria Aguda (IRA), diarrea, desnutrición, dengue, malaria, enfermedades inmunoprevenibles, maltrato infantil y alteraciones del crecimiento y desarrollo' ${ }^{1}$. En Colombia se adopta desde el año 1.999 a través del Ministerio de Salud para contribuir a disminuir la morbimortalidad en niños menores de cinco años, existiendo evidencias de su implementación en grandes ciudades como Bogotá, Cali, Medellín y Atlántico. Sin embargo, en la literatura científica son muy pocos los estudios que redactan estas experiencias, como el publicado sobre las prácticas hogareñas en el cuidado de la madre y el recién nacido en la Costa pacífica Colombiana ${ }^{2}$ y el relacionado con los conocimientos maternos sobre signos de peligro para la Enfermedad Diarreica Aguda (EDA) y evaluación de prácticas de hidratación en Popayán ${ }^{3}$. Esta estrategia se ha utilizado como herramienta de vigilancia epidemiológica y las directrices de implementación parten de las políticas de salud pública del país, logrando disminuir la muerte por EDA e IRA, los casos de neumonía y desnutrición, mediante capacitaciones a los profesionales de la salud, a las instituciones y a la comunidad en sus diferentes componentes.

Cartagena de Indias todavía presenta grandes carencias con respecto al desarrollo y socialización de la misma, sobre todo en algunas comunidades vulnerables aledañas a la ciudad como los corregimientos insulares de Barú y Caño del Oro (poblaciones de afro-descendientes dedicadas a la actividad pesquera y turística ${ }^{4}$ ). Los habitantes de estos corregimientos, constantemente reciben actividades de promoción de la salud para fortalecer el único centro de salud del sector público con que cuentan (dispone de un médico y un odontólogo general). Además, dadas las condiciones de infraestructura, geografía y poca disponibilidad de recursos físicos que garanticen una atención adecuada en salud, existe un importante porcentaje de niños que no son correctamente atendidos bajo el enfoque de riesgo. Además, muchas de las madres y de los cuidadores recurren a conocimientos empíricos y al saber de la comunidad para solucionar sus problemas de salud. Por ello, al realizar las jornadas de educación sobre la estrategia AIEPI, desde la Facultad de Odontología de la Universidad de Cartagena en estas comunidades, se buscó conocer si las madres sabían identificar los signos de peligros de las enfermedades prevalentes en niños menores de 5 años (la tos, diarrea y gripe) e identificar que prácticas realizaban frente a éstas.

Se realizó un estudio descriptivo transversal, encuestando a 127 madres de niños menores de 5 años. Se consideró que la madre presentaba prácticas adecuadas ante la tos persistente, la diarrea de un día de evolución y la fiebre de $38^{\circ} \mathrm{C}$ si se realizaba la medida sugerida ante el AIEPI más indicada (medida en casa) y se indagó de manera cualitativa sobre el uso de medicamentos y remedios caseros (líquidos tradicionalmente empleados en la región: agua de arroz tostado, aromáticas, caldos), suero de rehidratación oral (SRO) (en sobre o en líquido comercial) y suero casero (solución consistente en agua, sal y azúcar en proporciones recomendadas por la OMS).

Un $86,9 \%$ de las encuestadas no supieron identificar los signos de alarma de las enfermedades estudiadas y un $73,3 \%$ decidieron acudir al médico ante la presencia de estas patologías.

Respecto a las prácticas realizadas por las entrevistadas al inicio de estos procesos (tos, fiebre o diarrea), el $84,7 \%$ no puso en práctica las que se consideraron como adecuadas.

Por todo lo anterior, este tipo de comunidades vulnerables merecen especial atención por parte de los actores sociales y ameritan mayor dedicación y esfuerzo en la capacitación, implementación y evaluación de la estrategia AIEPI a través de vías de comunicación efectivas e innovadoras, que permitan su masificación y contribuyan a disminuir la morbimortalidad infantil. Su objetivo es buscar una atención integral en esta población a través de una prestación adecuada de servicios de salud con 
calidad, asignación permanente de profesionales, mejora de los comportamientos de los cuidadores de los niños y el aumento de factores protectores para la salud que permitan subsanar la distancia que hay hasta los centros de salud de segundo nivel que se encuentran en la ciudad y promuevan el desarrollo social de las comunidades. Esta estrategia es pertinente y eficaz, si se tiene en cuenta la situación crítica por la que atraviesa el sistema actual de salud que no responde a la demanda. Por último, es recomendable realizar estudios de investigación que demuestren el impacto de la estrategia en la comunidad y que se logre la socialización de los resultados ante las comunidades académicas para que faciliten su retroalimentación y la replicación de la misma a otras poblaciones.

\section{BIBLIOGRAFÍA}

1. Manual Clínico para el Aprendizaje de AIEPI en Enfermería (Atención Integrada de las Enfermedades Prevalentes de la Infancia.http://new.paho.org/per/images/stories/PER/ Documentos/manual\%20cl\%EDnico.pdf
2. Del Cairo C, Bedoya LM, Tabares RM, Delgado MF, Calvache J. Prácticas hogareñas en el cuidado de la madre y el recién nacido en la costa pacífica caucana. Antípoda: Revista de Antropología y Arqueología 2006; 3: 227-254

3. Delgado MF, Sierra CH, Calvache JA, Ríos ÁM, Mosquera $\mathrm{C}$, Salas I y cols. Conocimientos maternos sobre signos de peligro en diarrea aguda en el marco de la estrategia AIEPI. Colombia Médica 2006; 37: 293-298.

4. Alcaldía de Cartagena de Indias. Decreto 0977 del 2001. "Por medio del cual se adopta el Plan de Ordenamiento Territorial del Distrito Turístico y Cultural de Cartagena de Indias". 2001.

\section{Shyrley Díaz Cárdenas ${ }^{1}$, Katherine Arrieta Vergara ${ }^{2}$, Ketty Ramos Martínez ${ }^{3}$} 'Odontóloga Magister en Salud Pública.

Especialista en Salud Familiar y Gerencia en Salud ${ }^{2} \mathrm{OD}$, Magister en Salud Pública Especialista en Gerencia en Salud ${ }^{3} \mathrm{OD}$, Magister en Salud Pública, Especialista en Odontopediatría

Facultad de Odontología, Departamento de Odontología Preventiva y Social Universidad de Cartagena Cartagena de Indias, Colombia Correo electrónico: shyrley77@hotmail.com

\section{CAMBIO DE DIRECCIÓN}

Le rogamos nos avise con antelación en caso de cambio de dirección para no alterar el servicio de recepción de REVISTA CLÍNICA DE MEDICINA DE FAMILIA.

Los cambios deben comunicarse en el teléfono 967507911 o a través del correo electrónico info@scamfyc.org

\section{SUSCRIPCIONES Y ATENCIÓN AL CLIENTE}

SCAMFYC

Dionisio Guardiola, 16, 4 $\mathrm{D}$

02003- Albacete

Teléfono y Fax: 967507911

Correo electrónico: info@scamfyc.org

Tarifa de suscripción anual

Profesionales 40,00 Euros (IVA incluido)

Instituciones 120,00 Euros (IVA incluido) 